\title{
Tinjauan Hukum Islam Terhadap Tradisi Mayangi di Desa Puger Wetan Kecamatan Puger Kabupaten Jember
}

\author{
Via Nailatul Husna ${ }^{1}$ \\ ${ }^{1}$ Fakultas Syariah, IAIN Jember. E-mail: vianaila@gmail.com
}

\begin{tabular}{|c|c|}
\hline Article & Abstract \\
\hline $\begin{array}{l}\text { How to cite: } \\
\text { Via Nailatul Husna, } \\
\text { 'Tinjauan Hukum Islam } \\
\text { Terhadap Tradisi } \\
\text { Mayangi di Desa Puger } \\
\text { Wetan Kecamatan Puger } \\
\text { Kabupaten Jember' (2020) } \\
\text { Vol. } 1 \text { No. } 1 \\
\text { Rechtenstudent Journal } \\
\text { Fakultas Syariah IAIN } \\
\text { Jember. } \\
\text { Histori artikel: } \\
\text { Submit } 3 \text { Februari 2020; } \\
\text { Diterima } 1 \text { Maret 2020; } \\
\text { Diterbitkan } 3 \text { April 2020. }\end{array}$ & 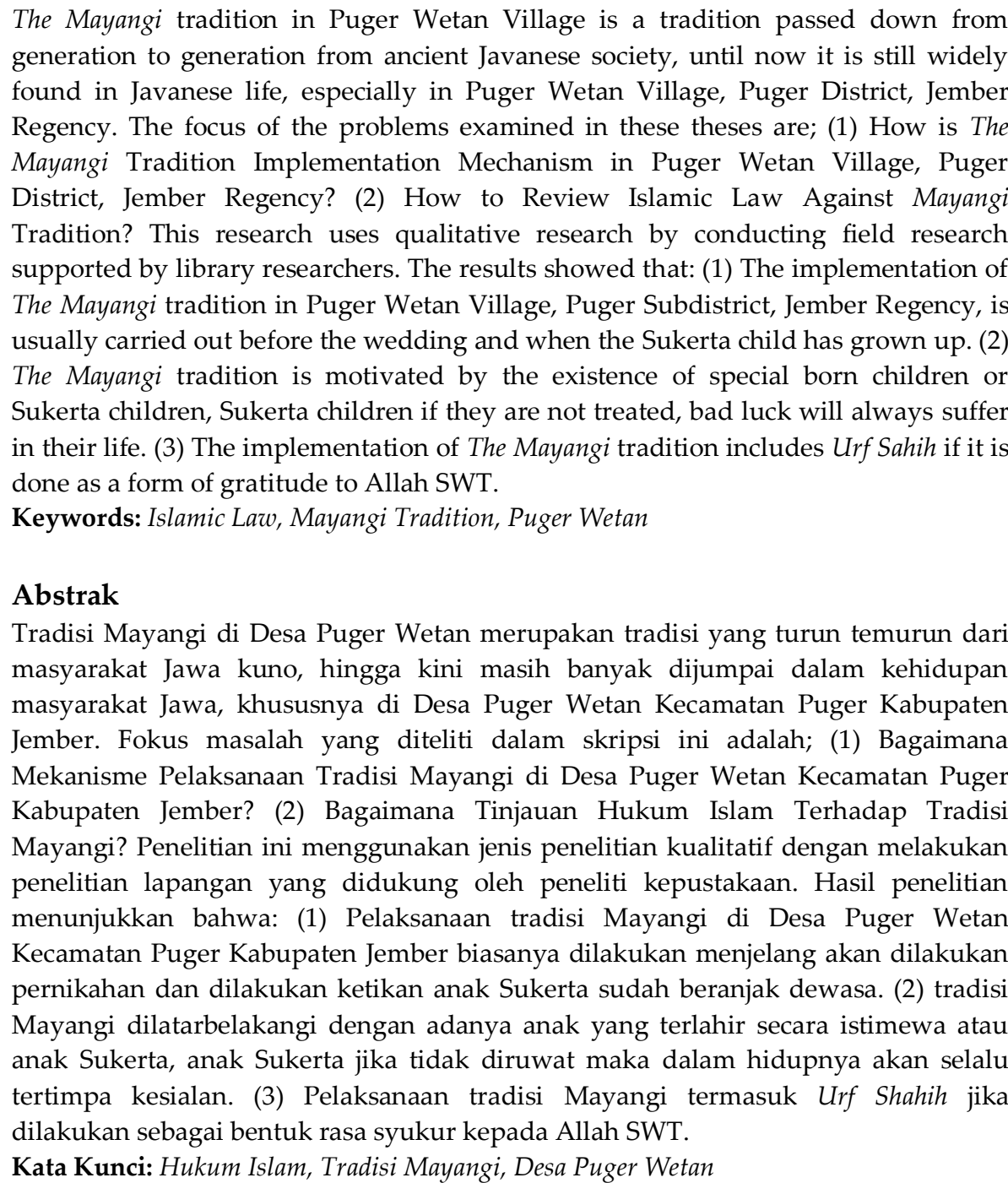 \\
\hline
\end{tabular}

\section{Pendahuluan}

Tradisi Mayangi adalah makna lain dari kata Ruwatan Sukerta, yang secara umum berarti upacara adat yang dilakukan bertujuan untuk menghilangkan dampak yang bisa berbentuk kesialan, menjauhkan segala kemungkinan yang buruk yang bisa terjadi jika seseorang tersebut termasuk orang yang harus diruwat. Sedangkan menurut bahasa tradisi Mayangi atau Ruwatan Sukerta terdiri dari dua kata. Diantaranya Ruwatan dan Sukerta. ${ }^{1}$

\footnotetext{
${ }^{1}$ Imam, Wawancara, Puger Wetan, 21 April 2018.
} 
Kata Ruwatan berasal dari bahasa Jawa "luwar saka panandhang, luwar saka wewujudan kang salah", yang artinya adalah terbebas dari wujud salah. Manusia yang tergolong ke dalam penderitaan itu berkaitan dengan berbagai hal atau kejadian yang tidak disengaja atau dikehendakinya. Misalnya, bila seseorang berbuat salah atau luar biasa dalam proses kelahirannya di dunia, orang semacam itu harus diruwat. Kedudukan orang yang tergolong ke dalam penderitaan itu dianggap dalam bahaya, yang jatuh dalam lembah malapetaka. Sebab itu mereka akan merasa takut dan waswas terutama bagi yang masih percaya. Sebaliknya bagi mereka yang tidak percaya bahkan sama sekali tidak tahu kalau dirinya tergolong orang yang terkena malapetaka. Tentu saja beban pikiran itu dengan sendirinya tidak pernah terjadi. Orang yang jatuh ke dalam penderitaan itu disebut dengan orang Sukerta. Kata suker dalam bahasa Jawa kuno artinya kotor, sedangkan "ta" adalah akhiran realis dalam tata bahasa jawa kuno yang artinya hendaknya dibersihkan kotorannya. Cara membersihkan kotoran itulah yang kemudian disebut sebagai upacara Ruwatan Sukerta (Mayangi). ${ }^{2}$

Masyarakat desa Puger Wetan melakukan tradisi Mayangi agar si anak nanti kehidupannya akan menjadi lebih baik ke depannya dalam menjalani kehidupan dan terhindar darimarabahaya dan kesialan. Biasanya tradisi Mayangi ini dilakukan apabila salah satu dari anak itu akan melakukan pernikahan, sebelum di adakan suatu pernikahan maka harus ada tradisi Mayangi terlebih dahulu, tapi sebagian masyarakat yang mengadakan tradisi Mayangi ini kapan saja kalau mereka benar-benar sudah berkeinginan mempunyai hajat untuk mengadakan tradisi Mayangi untuk anaknya. Dalam pandangan masyarakat Desa puger wetan bahwa kita bukan mendahului tadir Tuhan atau mendahului kehendaknya, tapi paling tidak kita berusaha semaksimal mungkin agar terhindar dari musibah yang akan terjadi pada kita. ${ }^{3}$

Mengamati secara cermat asal-usul kepercayaan Jawa tidaklah sederhana yang kita bayangkan. Kepercayaan jawa yang banyak bersentuhan dengan mistik itu, dalam realitasnya banyak menyimpan misteri yang sangat kompleks. Kompleksitas kepercayaan komunitas kejawen tidak jarang menampakkan berbagai sekte dan tradisi kehidupan dalam masyarakat Jawa. Sekte-sekte dan tradisi kehidupan itu sebagai bentuk manifestasi dari religiusitas masing-masing wilayah kejawen.

Mayangi sangat erat hubungannya dengan budaya Jawa Kuno, mamaca merupakan salah satu dari berbagai tradisi kejawen yang oleh beberapa masyarakat asli Jawa masih dilestarikan hingga saat ini, tidak lagi hanya dilaksanakan oleh masyarakat Jawa saja, di Puger Wetan misalnya, tradisi Mayangi masih sangat eksis hingga saat ini. ${ }^{4}$

Pemilihan Desa Puger Wetan Kecamatan Puger Kabupaten Jember sebagai lokasi penelitian karena dilatarbelakangi adanya keragaman suku yang secara umum masih melaksanakan tradisi Mayangi sebagai bagian tak terpisahkan dari seluruh aspek kehidupan yang dilaksanakan masyarakat desa tersebut. Keunikan ini menjadi daya tarik bagi penulis untuk menelusuri dengan melakukan penelitian yang bermuara pada pemahaman yang utuh tentang pelaksanaan Mayangi sehingga diharapkan mendapat gambaran yang tidak saja bisa dipahami dari sudut tradisi tetapi juga dapat dipahami dari sudut pandang agama Islam yang menjadi keyakinan masyarakatnya, yang pada gilirannya tradisi itu dapat dilestarikan dengan

\footnotetext{
2 Sri Teddi Rusdi, Ruwatan dan Ki Timbul Hadiprayitno (Jakarta Selatan: Yayasan Kertagama, Maret 2012$), 4$.

${ }^{3}$ Sri Teddi Rusdi, Ruwatan dan Ki Timbul Hadiprayitno (Jakarta Selatan: Yayasan Kertagama, Maret 2012 ), 7.

${ }^{4}$ Ragil Pamungkas, Tradisi Ruwatan (Yogyakarta: Narasi, 2008), 2.
} 
tidak menabrak norma-norma agama islam. atau dengan kalimat lain merusak aqidah masyarakat yang melaksanakan Mayangi tersebut.

Dalam penelitian ini, hukum pelaksanaan Mayangi akan dikaji dalam perspektif Hukum Islam dengan menggunakan istimbath hukum yang berlandaskan pada kaedah ushuliyah dan kaidah fighliyah.

\section{Rumusan Masalah}

Adapun rumusan masalah dalam penelitian ini adalah:

1. Bagaimana pelaksanaan tradisi Mayangi di Desa Puger Wetan Kecamatan Puger Kabupaten Jember?

2. Mengapa masyarakat Desa Puger Wetan Kecamatan Puger Kabupaten Jember melakukan tradisi Mayangi?

3. Bagaimana tinjauan Hukum Islam terhadap pelaksanaan tradisi Mayangi di Desa Puger Wetan Kecamatan Puger Kabupaten Jember.

\section{Metode Penelitian}

Pendekatan yang digunakan penulis pada penelitian ini adalah pendekatan kualitatif. Pendekatan kualitatif merupakan suatu metode penelitian yang bermaksud memahami fenomena tentang kondisi objek yang alamiah oleh subjek penelitian misalnya tindakan dan lain-lain secara holistik dan dengan cara deskripsi. Atau secara sederhana penelitian kualitatif mengandung pengertian adanya upaya penggalian dan pemahaman pemaknaan terhadap apa yang menjadi objek penelitian.

Jenis penelitian yang akan digunakan adalah penelitian lapangan (field research), yaitu penelitian yang objeknya mengenai gejala-gejala atau peristiwa-peristiwa yang terjadi pada kelompok masyarakat.

Jenis penelitian ini menggunakan penelitian yang bertujuan membuat deskripsi atau gambaran mengenai fakta-fakta, sifat-sifat serta hubungan atau fenomena yang diselidiki, penelitian deskriptif menggambarkan "apa adanya" tentang suatu variable, gejala atau keadaan.

\section{Hasil dan Pembahasan}

\section{Mekanisme Pelaksanaan Tradisi Mayangi di Desa Puger Wetan Kecamatan Puger Kabupaten Jember}

Setelah melakukan penelitian, peneliti dapat mendeskripsikan bahwa mekanisme tradisi Mayangi yang ada di Desa Puger Wetan Kecamatan Puger Kabupaten Jember dengan menggunakan sarana dan prasarana seperti kembang tujuh rupa, pisang satundun yang sudah matang, api (batu arang), ${ }^{5}$ kain mori abang dan mori putih (kain kafan warna putih atau warna merah) yang digunakan sebagai kain penutup kepala pada saat siraman dan digunakan untuk penutup tirai pada saat acara pewayangan dilaksanakan, selendang, jajanan pasar sebanyak tujuh macam, peralatan dapur lengkap, tebu wulung, satu buah kelapa utuh, satu tangkai buah jambe, bubur nasi warna merah dan putih, bubur nasi warna lima (selain warna merah dan putih), ayam panggang utuh, nasi liwet, pisang raja, pisang ayu utuh satu tundun, bumbu dapur, air sumur tujuh sumber (untuk memandikan anak Sukerta), air laut

${ }^{5}$ Sri Teddy Rusdy, Ruwatan Sukerta dan Ki Timbul Hadiprayitno, (Jakarta Selatan: Yayasan Kertagama, Maret 2012), 35. 
satu gelas, payung, tikar, bantal, uang koin, peralatan make up untuk anak Sukerta laki-laki dan perempuan, dan bambu kuning sebanyak lima ruas. Tradisi Mayangi ini dilakukan kepada anak Sukerta (anak yang diganggu dengan kesialan selama hidupnya), dengan tujuan memohon doa kepada Allah SWT agar dijauhkan mara bahaya. Mekanisme pelaksanaan tradisi Mayangi yang ada di Desa Puger Wetan Kecamatan Puger Kabupaten Jember, dalam pelaksanaan tradisi Mayangi diawali dengan anak Sukerta melakukan puasa yang namanya LAKU TARAK yaitu puasa dari makanan daging, telur, ikan atau makanan yang bernyawa selama tujuh hari sebelum acara ruwatan Sukerta dilaksanakan. Namun, jika anak tersebut tidak bisa melakukan LAKU TARAK maka alternatif lain adalah dengan cara berpuasa selama 24 jam H-1 (sebelum hari H). Dengan melakukan puasa 24 atau LAKU TARAK dianjurkan pula kepada anak Sukerta untuk lebih mendekatkan diri kepada Tuhan Yang Maha Esa, sholat, dan berdoa agar acara berjalan dengan lancar tanpa adanya hambatan apapun, selanjutnya setelah dimulainya acara ruwatan awal pembukaan dibuka dengan acara tahlilan (pembacaan surat yasin dan ayat-ayat suci Al-Quran) yang dipandu oleh pak Kyai atau tokoh masyarakat, selanjutnya dilaksanakan acara sungkeman anak Sukerta kepada kedua orang tua. Dengan diiringi dengan Sholawat Nabi anak Sukerta melakukan sungkeman kepada kedua orang tuanya dengan tujuan agar setiap jalannya acara mendapatkan ridha orang tua. Setelah acara sungkeman selesai dilanjutkan dengan prosesi siraman kepada anak Sukerta yang dipimpin oleh Dalang ruwat atau yang biasanya disebut dengan Dalang Sejati, dalam prosesi siraman ada beberapa tahap diantaranya:

a. Pembukaan dan sambutan yang disampaikan oleh Dalang Ruwat.

b. Pembacaan doa-doa.

c. Pembakaran kertas yang bertuliskan mantra-mantra jawa dan arab raja oleh anak Sukerta (anak yang akan diruwat).

d. Abu dari pembakaran kertas itu tadi dimasukkan kedalam wadah yang berisikan air, lalu diteteskan ke atas kepala anak Sukerta oleh Dalang Ruwat.

e. Pemotongan rambut anak Sukerta yang dilakukan oleh dalang ruwat.

f. Anak Sukerta (anak yang akan diruwat) dipakaikan kain mori putih (kain kafan), cara pemakaiannya seperti ikhram dan diletakkan diatas kepala layaknya orang mau melangsungkan akad nikah.

g. Sebelum memandikan anak Sukerta, kedua orang tua anak tersebut membacakan ayatayat suci Al-Quran, doa, dan juga mantra-mantra Jawa terlebih dahulu yang akan dipandu oleh Dalang ruwat. 6

h. Setelah selesai anak Sukerta dimandikan dengan kembang tujuh rupa, banyu sumur (air sumur) 7 sumber dan air laut satu gelas. Semua persyaratan dicampurkan menjadi satu yang dinamakan air tempur (campuran air sumur 7 sumber dan satu gelas air laut). ${ }^{7}$

i. Dalam menyiramkan air tempur dan bunga tujuh rupa kepada anak Sukerta, Dalang dengan mengucap (Ya Allah, singkirkanlah segala bencana dariku) dibaca sebanyak tiga kali. Setelah itu dilanjutkan dengan membaca mantra "Sun lelaku penyucen kanggo ragaku, sukmo lan jiwoku pantes kersane Gusti Kang Maha Esa" (Aku bersuci untuk ragaku, sukma dan jiwaku sesuai kehendak Tuhan Yang Maha Esa). Doa mandi ruwat

${ }^{6}$ Sri Teddy Rusdy, Ruwatan Sukerta dan Ki Timbul Hadiprayitno, (Jakarta Selatan: Yayasan Kertagama, Maret 2012), 37.

${ }^{7}$ Sri Teddy Rusdy, Ruwatan Sukerta dan Ki Timbul Hadiprayitno, (Jakarta Selatan: Yayasan Kertagama, Maret 2012), 38. 
ini dibacakan oleh Dalang ruwat dan diikuti oleh anak yang bersangkutan dan kedua orang tua anak tersebut. Hal ini dilakukan dengan harapan agar dapat memberikan keberkahan untuk keluarga anak yang diruwat. Setelah prosesi upacara siraman selesai anak tersebut diarak oleh semua warga dan juga kedua orang tuanya untuk dibawa kepertigaan desa. Hal ini dilakukan dengan tujuan untuk membuang sengkolo di pertigaan desa karena tempat berkumpulnya roh-roh gaib. Setelah itu si anak yang bersangkutan diwajibkan untuk memakai pakaian-pakaian baru pengganti yang telah disiapkan oleh Dalang. Dengan harapan si anak tersebut memulai lembaran baru dalam hidupnya yang penuh berkah dan kebahagiaan yang selalu menyertainya.

j. Setelah upacara siraman selesai, Dalang meminta pakaian atau baju bekas anak Sukerta yang terakhir dipakai untuk dihanyutkan ke sungai atau ke laut, dengan tujuan agar Kala (kesialan) yang menimpa anak tersebut hilang terbawa arus.

k. Setelah upacara siraman anak Sukerta selesai biasanya masyarakat Desa Puger Wetan Kecamatan Puger Kabupaten Jember melakukan pengarakan kepada anak Sukerta ke pertigaan Desa tempat anak tersebut tinggal. Dengan membawa sesajen yang berisikan (bubur warna putih dan merah dan bubur yang terdiri dari lima warna, bukan termasuk warna putih dan merah), serta sisa air yang digunakan untuk siraman dimasukkan ke dalam kendi kecil, kemudian sesajen tersebut diletakkan di pertigaan desa dimana anak Sukerta itu tinggal. Setelah selesai penempatan sesajen anak Sukerta diarak kembali menuju tempat tinggalnya dan dianjurkan untuk mengganti pakaian, dan mencuci kain mori yang dibuat ikhram itu tadi lalu disimpan di dalam lemari atau juga bisa diberikan kepada Dalang Sejati (dalang yang dipercaya untuk melaksnakan ruwatan). ${ }^{8}$

1. Selanjutnya, setelah upacara siraman selesai Dalang meminta kepada salah satu keluarga anak Sukerta agar menancapkan bambu kuning yang berjumblah lima tangkai agar di letakkan ke lima titik sudut rumah anak Sukerta, dengan meletakkan kacang hijau, kedelai hitam, ikan asin, kluwek, kemiri, telur ayam, dan uang koin. ${ }^{9}$

Tujuan dilakukannya siraman kepada anak Sukerta untuk mensucikan diri agar terhindar dari Kala (kesialan). Acara siraman dilakukan pada siang hari jam 12:00 WIB. Setelah acara siraman selesai dilakukan pada malam harinya pada jam 00:00 WIB malam hari diadakan pagelaran wayang yang dipandu oleh Dalang Sejati.

\section{Mengapa Masyarakat Desa Puger Wetan Kecamatan Puger Kabupaten Jember Melaksanakan Tradisi Mayangi}

Mengenai alasan mengapa masyarakat Desa Puger Wetan Kecamatan Puger Kabupaten Jember melakukan tradisi Mayangi dikarenakan beberapa faktor yang melatar belakanginya diantaranya anak ontang anting (anak tunggal), tawang gantung (anak yang lahir kembar namun berselang hari), wungkus (anak yang lahir di bungkus), wungkul (anak yang lahir tanpa ari-ari), saromba (empat anak yang berjenis kelamin laki-laki semua), serimpi (empat anak yang berjenis kelamin perempuan semua), dll. Masyarakat Desa Puger Wetan Kecamatan Puger Kabupaten Jember percaya bahwasanya jika anak tersebut tidak diruwat maka kehidupannya atau sepanjang hidupnya akan tertimpa kesialan yang bertubi-tubi.

\footnotetext{
${ }^{8}$ Sri Teddy Rusdy, Ruwatan Sukerta dan Ki Timbul Hadiprayitno, (Jakarta Selatan: Yayasan Kertagama, Maret 2012), 40.

${ }^{9}$ Sri Teddy Rusdy, Ruwatan Sukerta dan Ki Timbul Hadiprayitno, (Jakarta Selatan: Yayasan Kertagama, Maret 2012), 41.
} 
Biasanya anak tersebut akan diruwat jika anak tersebut akan melangsungkan pernikahan atau anak tersebut sudah beranjak dewasa. Tradisi Mayangi ini sudah mendarah daging di kalangan masyarakat Desa Puger Wetan Kecamatan Puger Kabupaten Jember, dan masyarakat percaya jika anak yang lahir termasuk dalam anak Sukerta maka anak tersebut harus diruwat. ${ }^{10}$

\section{Tinjauan Hukum Islam Tentang Tradisi Mayangi}

Setelah dilakukannya penelitian dalam tinjauan hukum islam, tradisi Mayangi di Desa Puger Wetan Kecamatan Puger Kabupaten Jember termasuk dalam urf Shahih yang artinya urf yang dapat diterima dengan baik karena tidak bertentangan dengan syara'. Karena sudah jelas di dalam mekanisme pelaksanaan tradisi Mayangi di Desa Puger Wetan Kecamatan Puger Kabupaten Jember mengandung unsur keislaman seperti halnya sebelum acara dimulai masyarakat Desa Puger Wetan Kecamatan Puger Kabupaten Jember menggelar acara tahlilan, yang dimana di dalam acara tahlilan itu ada pembacaan surat Yasin dan ayat suci al-Quran, serta adanya pembacaan Shalawat Nabi. Suatu perbuatan atau tindakan dapat dikategorikan sebagai Urf Shahih karena hal tersebut sudah menjadi kebiasaan yang berlaku dalam masyarakat, yang sesuai dengan A. Djazuli adat yang diakui adalah yang umumnya terjadi dan dikenal oleh manusia bukan dengan yang jarang terjadi. Kaidah yang dipahami dalam menjadikan suatu ketentuan yang menjadi dasar atau pegangan untuk melakukan sesuatu, harus sesuatu yang sudah ada pada zaman dahulu dan yang sudah dikenal oleh masyarakat luas. Dalam hal ini tradisi Mayangi yang ada di Desa Puger Wetan Kecamatan Puger Kabupaten Jember sudah biasa dilakukan untuk mensucikan jiwanya dari pengaruh buruk. Serta tidak bertentangan dengan Nash dan al-Quran maupun Hadist, dan mendatangkan kemaslahatan dan menjauhkan kemudharatan. ${ }^{11}$

Berdasarkan argumen diatas dapat dinyatakan bahwa tradisi Mayangi di Desa Puger Wetan Kecamatan Puger Kabupaten Jember dikatakan sebagai Urf Shahih karena telah memenuhi beberapa syarat dan beberapa ketentuan yang sudah dijelaskan bahwasanya Urf shahih adalah suatu tradisi atau kebiasaan masyarakat yang tidak bertentangan dengan AlQur'an dan Hadist, serta tidak menghalalkan yang haram dan atau tidak pula menggugurkan kewajiban.

\section{Kesimpulan}

Dari pembahasan di atas, ada beberapa kesimpulan yang dapat diambil antara lain:

1. Mekanisme pelaksanaan tradisi Mayangi yang ada di Desa Puger Wetan Kecamatan Puger Kabupaten Jember, dalam pelaksanaan tradisi Mayangi diawali dengan acara tahlilan (pembacaan surat yasin dan ayat-ayat suci Al-Quran) yang dipandu oleh pak Kyai atau tokoh masyarakat, selanjutnya dilaksanakan acara sungkeman anak Sukerta kepada kedua orang tua. Dengan diiringi dengan Sholawat Nabi anak Sukerta melakukan sungkeman kepada kedua orang tuanya dengan tujuan agar setiap jalannya mendapatkan ridha orang tua. Setelah acara sungkeman selesai dilanjutkan dengan prosesi siraman kepada anak Sukerta yang dipimpin oleh Dalang ruwat atau yang biasanya disebut dengan Dalang Sejati.

\footnotetext{
${ }^{10}$ Wiji Saksono, Mengislamkan Tanah Jawa Tela'ah Atas Metode Dakwah Walisongo (Jakarta: Mizan, 1999), 43.

${ }^{11}$ Noor Harisudin, Ilmu Ushul Figh (Pena Salsabila, 2014), 112.
} 
2. Tradisi Mayangi di Desa Puger Wetan Kecamatan Puger Kabupaten Jember, dilatarbelakangi dengan adanya anak Sukerta (anak yang terkena Kala) dan jika anak tersebut tidak diruwat maka sampai kapanpun anak Sukerta akan menjadi mangsaan Bethara Kala, maka dari itu alasan masyarakat Desa Puger Wetan Kecamatan Puger Kabupaten Jember melakukan tradisi Mayangi.

3. Pelaksanaan tradisi Mayangi di Desa Puger Wetan Kecamatan Puger Kabupaten Jember termasuk Urf Shahih karena dilakukan sebagai bentuk rasa syukur kepada Allah SWT, ditujukan untuk mendekatkan diri kepada Allah SWT, ditujukan sebagai lambang kesatuan sosial masyarakat dalam menjalin hubungan antar masyarakat, sebagai media bersedekah kepada masyarakat, serta ruwatan digunakan sebagai media untuk berdakwah. Hal tersebut termasuk kebiasaan masyarakat setempat, yang tidak bertentangan dengan syara' dan mendatangkan kemaslahatan.

\section{Daftar Pustaka}

\section{Buku}

Anonim. 2015. Pedoman Penulisan Karya Ilmiah, Jember: IAIN Jember Press.

Harisudin Noor. 2014. Ilmu Ushul Figh, Surabaya: Pena Salsabila.

Nazir Muhammad. 2005. Metode Penelitian, Jakarta: Galhia Indonesia.

Pamungkas Ragil. 2008. Tradisi Ruwatan, Yogyakarta: NARASI.

Patimura Hamid. 2011. Metode Penelitian Kualitatif Edisi Revisi, Bandung: ALFABETA.

Saksono Wiji. 1999. Mengislamkan Tanah Jawa Tela'ah Atas Metode Dakwah Walisongo, Jakarta: Mizan.

Subagyo Joko. 1997. Metode Penelitian Dalam Teori dan Praktek, Yogyakarta: PT Dana Bhakti Wakaf. 